\title{
RELATIVE PRICE CHANGES AND THE BENEFITS AND COSTS OF ALTERNATIVE POWER PROJECTS
}

\author{
Gunter Schramm ${ }^{1}$
}

\section{INTRODUCTION}

In the evaluation of federal water resources projects it is general practice to state all benefits and costs in terms of current prices. Usually no attempt is made to take account of either absolute or relative price changes. The problem, of course, has long been recognized. Senate Document 97 states explicitly: "The prices used for project evaluation should reflect the exchange values expected to prevail at the time costs are incurred and benefits accrued. ${ }^{2}$ However, recognizing the difficulties in arriving at future cost and price projections, the Senate document continues: "Pending development of mutually acceptable long-term price projections of this type, normalized current price relationships may be used in estimating deferred project effects. "3 So far, unfortunately, the use of "expected exchange values" has remained a statement of intent, rather than policy.

This paper investigates the possible consequences of the use of current, rather than expected future price relationship and shows, on the basis of some well-documented project evaluations for potential Alaskan hydro power developments, that this omission can lead to considerable economic inefficiencies in the selection pattern and evaluation of alternative projects. ${ }^{4}$

Data from three alternative Alaskan power projects, the Rampart and the Yukon-Taiya hydro-electric power projects and a hypothetical large-scale natural gas-fired thermal powerplant have been utilized for illustrative

$1_{\text {The author is Associate Professor of Resource Economics at the }}$ University of Michigan, Ann Abor, Michigan. The financial support of a Resources for the Future Inc., Fellowship and a research grant by the Canadian Department of Energy, Mines and Resources is gratefully acknowledged. Saul $\mathrm{H}$. Hymans and Micheal Laub made many helpful suggestions while Miss Elizabeth Gardiner provided valuable research assistance.

${ }^{2}$ Policies, Standards, and Procedures in the Formulation, Evaluation and Review of Plans for Use and Development of Water and Related Land Resources. Senate Doc. 97, 87th Congress, 2nd Session, Wash. 1962, p. 12.

${ }^{3}$ Ibid.

${ }^{4}$ Because of space limitations the analysis is limited to the evaluation of alternative electric power generating plants. For a discussion of the effects of likely increases in benefits over time see: John V. Krutilla, "Conservation Reconsidered," The American Economic Review, Vol. LVII, No. 4, Sept. 1967 and Denny S. Parker \& James A. Crutchfield, "Water Quality Management and the Time Profile of Benefits and Costs, "Water Resources Research, Vo. 4, No. 2, April, 1968. 
purposes. ${ }^{5}$ These empirical data have been used strictly as a matter of convenience. No policy implications for these specific projects are intended. ${ }^{6}$

\section{GENERAL PRICE LEVEL CHANGES}

Let us first look at the effects of changes in the general price level. This is an issue that has found some attention in the literature. ${ }^{7}$ Hydro-power projects are characterized by a preponderance of capital expenditures relative to operating expenditures. In the case of the proposed Yukon-Taiya project, for example, estimated capital expenditures amount to almost 89 percent of total costs. Typically, these expenditures take place at the early stages of overall project life, whereas the benefits, i.e. the revenues from power sales, are distributed over the life expectancy of the project. Given a gradual, but apparently inexorable rise in the general price level, evaluation of benefits and costs in current dollar terms will under-estimate the former since they would be subject to the general price escalation. On the other hand, present long-term interest rates likely reflect current expectations of future price increases, i.e., they include an additional premium to cover anticipated inflationary losses. ${ }^{8}$ If this is the case, and if the benefit values are not price adjusted then the present value of future benefits are seriously underestimated. This could lead to the elimination of projects which in real terms would be economically efficient. Two methods have been suggested by which these distortions could be eliminated. One would be to evaluate the project explicitly in terms of current price levels and adjust the discount rate downward. This is a relatively simple procedure once the inflationary portion of the discount rate has been isolated. The other would be to use the market rate of discount, but

${ }^{5}$ Data from: U. S. Dept. of the Interior, Rampart Project Alaska, Field Report, Juneau, Jan. 1965, and Gunter Schramm, "The Economics of an Upper Yukon Basin Power Development Scheme," Annals of Regional Science, Vol.II, No. 1.

6

Construction of Rampart has already been rejected as uneconomic on the basis of conventional criteria. See U. S. Dept. of the Interior, Alaska Natural Resources and the Rampart Project, Wash. D. C., June 1967. For YukonTaiya new and upgraded cost estimates are needed.

${ }^{7}$ See, for example, J. Hirshleifer, J. C. de Haven, J. W. Milliman, Water Supply, Univ. of Chicago Press, 1960, p. 142-4 and G. L. Reuber and R. J. Wonnacott, The Cost of Capital in Canada, Resources for the Future Inc. Wash. D. C., 1961, p. 9 ff.

8

${ }^{H}$ Hirschleifer, et. al., have estimated that this premium amounts to approximately one-half of one percent per annum. (Hirshleifer, et. al., op. cit.) Under today's conditions of high borrowing costs and strong inflationary pressures it is likely to be substantially higher. 
to adjust future benefits and costs by the appropriate inflator. ${ }^{9}$ However, this analysis and the suggested remedies are appropriate only if (a) future relative prices are expected to be the same as current relative prices, and (b) the applied discount rate really reflects the average current market rate. Neither of these requirements were met in recent years. While there is little doubt that the general price level will continue to rise, generating costs of electricity are expected to fall not only in constant but also in current prices. ${ }^{10}$ Furthermore, at least until President Johnson's 1968 budget proposal request for a more realistic rate, federal discount rates were considerably lower than the actual long-term federal borrowing rate. 11 This subsidy element in the computed federal rates applied to water resources projects more than compensated for any existing bias resulting from general price level changes. For both reasons, therefore, a downward revision of the applied discount rate would have been and is likely to remain inappropriate.

\section{RELATIVE PRICE CHANGES}

Relative price changes are the result of the complex interaction of many variables. While these changes are related to and are being reinforced by the general upward drift in prices they would occur even if the average price level would remain constant or fall. We live in an economy whose total as well as per capita real output is growing almost constantly. This growth is brought about by increases in our population, in our stock of capital and by changes and improvements in technology and educational skills. Growth in market size makes possible the rapid introduction of new technological improvements. It also makes possible the utilization of economies of scale in production. But technological changes as well as economies of scale differ substantially among different sectors and production processes whereas wage rates and returns to

${ }^{9}$ Both methods will yield approximately the same adjusted present value of benefits provided the estimated inflated portion of the discount rate is equal to the expected average annual percentage rise in prices.

It is also conceivable, however, that current market estimates of future real and inflationary returns to capital are wrong. If, for example, the real interest rate rises in the future, some projects undertaken now may ex post turn out to be inefficient investments. Ideally, all benefits and costs should be evaluated in terms of one-year expected real rates for each future year. The long-term real average rate then is a geometric average of $M$ years' one-year rates.

${ }^{10}$ See Gunter Schramm, "The Effects of Low-Cost Hydropower on Industrial Location," Canadian Journal of Economics, Vol. II, No. 2, May 1969.

${ }^{11}$ For a discussion of some of the consequences see: John Krutilla, "Is Public Intervention in Water Resources Development Conducive to Economic Efficiency?", Natural Resources Journal, Jan. 1966. 
capital by and large do not, at least in the long run. ${ }^{12}$ To discuss the underlying causes of relative price changes is beyond the scope of this paper. ${ }^{13}$ Here we can do no more than to investigate whether such price changes are likely to occur in sectors that will affect the production of electric energy.

Figures 1 and 2 show a number of construction labor and material related price indexes. The most significant aspects of these indexes are the almost constant increase in monetary costs and prices in almost all sectors on the one hand and the wide divergence in the long-term rate of increase among them on the other. As we will see below both factors can have a profound effect on the real benefits and costs from a given project. ${ }^{14}$

Ordinarily, an analysis of the consequences of relative price changes would require that full account is taken of general price level changes as well. This could be done by one of the two adjustment procedures suggested above. Appendix $\mathrm{B}$ contains some generalized models that outline the necessary methodology. However, this approach cannot be used for a comparative evaluation of the Alaskan projects under investigation here. Because of their immense size relative to the existing power market ${ }^{15}$ the federal agencies made no attempt to assign a market value to the output, which would have been a necessary prerequisite for a standard benefit-cost analysis. Instead, the projects were analyzed and compared on the basis of their estimated minimum average mill-rates per kilowatt-hour that would have to be charged in order to assure repayment of project costs. Feasibility tests then consisted of a

${ }^{12}$ If they did then labor and investment capital would gradually move over into the more remunerative sectors. This means that a technologically stagnant production process or sector would either cease to exist or would have to raise prices (if there are no close substitutes for the output).

13

${ }^{13}$ For a more detailed discussion of the inter-action of technological change, changes in wage rates and inflationary pressures see, for example, Charles L. Schultze, "Recent Inflation in the United States, " Study of Employment, Growth and Price Levels, U. S. Congress, Study Paper No. 1, 1959, and O. Eckstein and Th. Wilson, "The Determination of Money Wages in American Industry," The Quarterly Journal of Economics, Aug. 1962.

${ }^{14}$ We have to assume, however, that relative price changes reflect changes in real cost of resources rather than changes in monopoly rents, for example.

${ }^{15}$ Rampart's estimated energy output, for example, was almost forty times larger than the total 1962 energy consumption within its projected Alaskan marketing area. Data from: Gunter Schramm, "Electric Power Demand and Supply in Alaska and the Pacific Northwest, "Vol. IV of Stephen H. Spurr, et. al., Rampart Dam and the Economic Development of Alaska, The University of Michigan, School of Natural Resources, Ann Arbor, March 1966 , p. 8-1. 
number of forecasts which tried to establish whether sufficiently large power markets could be found or created to assure marketing at that minimum rate ${ }^{16}$ Furthermore, the applied interest rate of three percent was an administratively determined one which makes it unlikely that it represented either the real or the market rate. ${ }^{17}$ In order to trace the consequences of expected component cost changes on minimum average mill rates and maintain compatibility of the findings with the original agency estimates it is necessary to undertake the analysis within the same accounting and evaluation framework that was utilized before. What this means, in essence, is that no account is taken of the possible effects of general price level changes on the future value of outputs. ${ }^{18}$ Given the nature and purpose of the projects this omission can be justified because it would have been difficult if not impossible to establish the real value of their production.

\section{CHANGES IN CAPITAL COSTS}

Figure 1 includes a composite Reclamation Bureau price index which refers to a hypothetical hydropower project of average representative size. The average long-term rate of cost increases of this index is about two percent per annum, a rate which will have only a relatively small influence on the capital costs of smaller or medium-sized projects whose construction and installation take only a few short years. Furthermore, these overall inflationary changes will likely be swamped by the short-term fluctuations in bidding and contract prices which are a function of capacity utilization in the construction and equipment industry at the time of construction. Moreover, in cases where construction periods of alternatives are roughly equivalent and where the relative shares of capital costs and operating expenditures are similar such construction cost increases will influence the various alternatives in the same manner so that no significant changes in the relative ranking of projects will take place.

However, these conditions do not hold in the case of major hydro developments whose construction time horizon varies substantially from that of other alternatives. Let us investigate the probable impact of construction cost

${ }^{16}$ Any large-scale sales contracts with new electro-process industries or southern utilities would have required long-term, fixed price agreements without price escalator clauses. From a contractual point of view, therefore, potential general price level changes would have had no effect on project feasibility. Furthermore, the expected future reduction in thermal power costs would have reduced the real value of the project's output in any case.

${ }^{17}$ See also John Krutilla, op. cit.

${ }^{18}$ This procedure would also be appropriate if it could be assumed that (a) the general price level will remain unchanged and (b) the applied interest rate is equal to both the expected real and the expected market rate. 

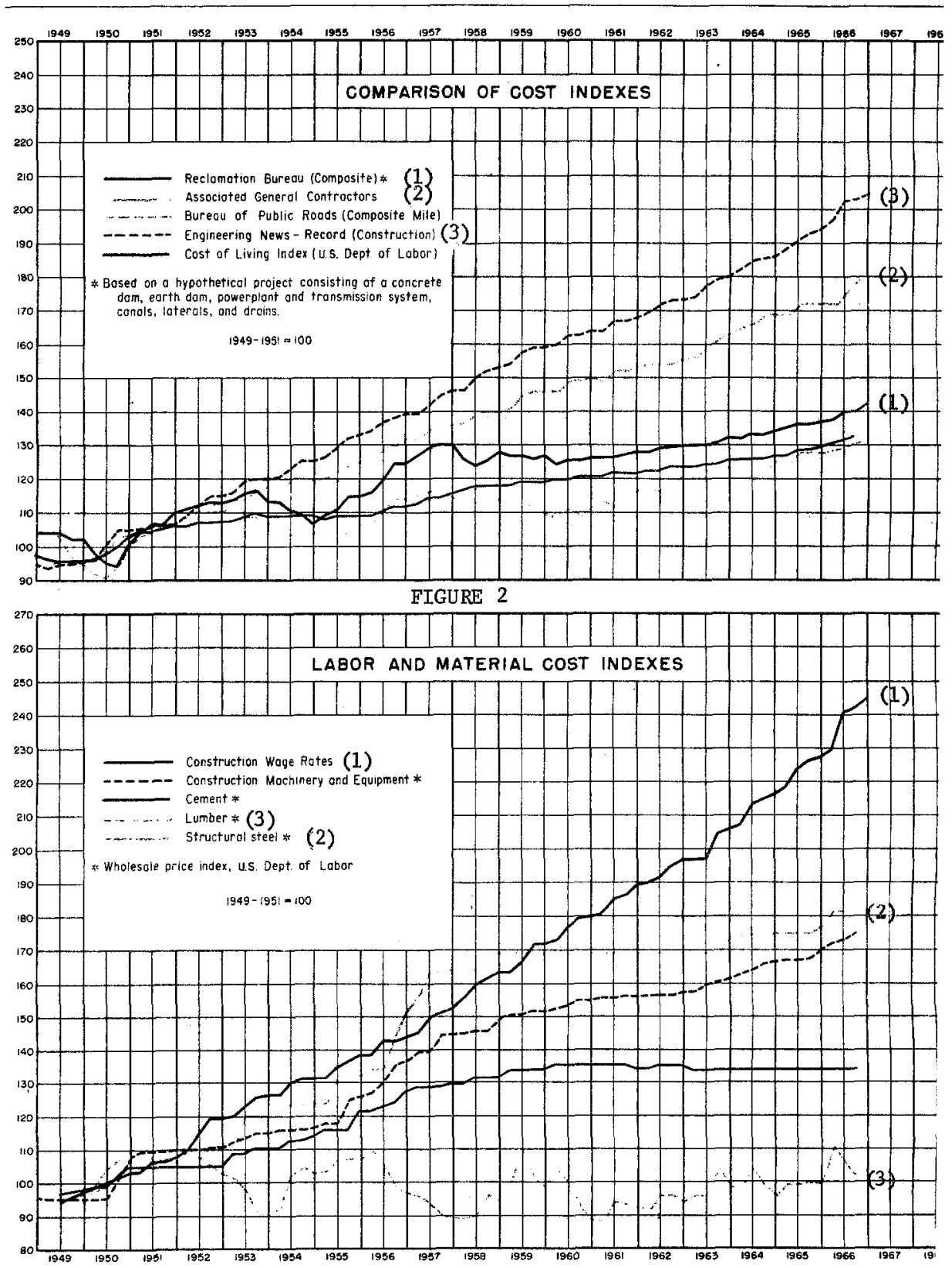

Reproduced from: U.S.Department of the Interior,Bureau of Reclamation, Construction Cost Trends, Jan. 1967 
changes on our two hydro alternatives, Rampart and Yukon-Taiya.

Since the construction industry probably has shown less dramatic technological improvements than many of the manufacturing sectors, price increase in this industry - as a result of rising factor costs - would have to be higher than price increases in the economy as a whole, an observation which is supported by the rapid advance of construction cost price indexes. The Associated General Contractors and the Engineering News-Record price indexes shown in figure (1) can serve as examples. 19 However, it has often been claimed that construction cost indexes really overstate price increases since they are based on input prices only and, therefore, completely neglect the effects of whatever technological improvements do occur. 20 These objections are certainly justified. For this reason an output oriented price index made up of completed component prices, such as the Bureau of Reclamation's composite index is likely to provide a better measure of actual cost changes. It would be better still to make use of the more detailed component indexes also provided by the Bureau but this would require a detailed cost breakdown for each project not only by item but also by time schedule. Such a breakdown is not available.

${ }^{19}$ They indicate $1949-51$ to 1966 average annual increases of about $3-1 / 2$ and $4-1 / 2 \%$ respectively. In the same period the wholesale price index rose only by 1 and the consumer price index by $1-3 / 4 \%$. As can be seen from figure 2 the cost increases of several major construction inputs were particularly rapid. Structural steel rose by $3-3 / 4$, construction machinexy by $3-1 / 2$, cement by 2 and wage rates by $6 \%$ per annum. Only lumber prices remained constant. According to Department of Labor figures gross average weekly earnings in contract construction rose by $5 \%$ compared to $4-1 / 2 \%$ in manufacturing and $4 \%$ in all private sectors combined. This consistent and more rapid advance of construction wages took place despite a much higher unemployment rate which, according to Haveman and Krutilla, between 1957 and 1964 ranged from 9.8 to $14.1 \%$ compared to a U. S. all-industrial average of 4.3 to $6.7 \%$. Labor costs for hydro projects could, depending on the type of construction, account for up to $40 \%$ or more of total project costs. Data from: (a) figure 2, (b) U. S. Dept. of Labor, Bureau of Labor Statistics, Employment and Earnings Statistics for the United States 1909-68, Wash. D. C., 1967, table 4, p. XXVI, National Industrial Conference Board, Economic Almanac 1967-1968, The Macmillan Co., New York, 1967, pp. 103-109, (c) Robert H. Haveman \& John V. Krutilla, Unemployment, Idle Capacity, and the Evaluation of Public Expenditures, Johns Hopkins Press, Baltimore, 1968, tables 1 and 6 .

20

Most of these indexes are based on a weighted average of cement, lumber, structural steel, and common labor costs. For this reason they can only account for technological improvements in the production of these specific materials as reflected by their prices. They do not take account of the prices of other inputs, or of technological advances in combining all types of inputs in the process of actual construction. 
Nevertheless, while the use of a composite index can only provide an approximation, an approximation moreover which only tells us what happened in the past, the rather predictable fact of further price increases in the future renders the use of such an index preferable to the use of current price and cost relationships.

Three alternatives have been investigated. In the case of Rampart they are Field Report projections Case I(A) and Case II(A). The former was based on the most conservative load growth forecast whereas the latter presumed a pattern of load growth that would have fully utilized the hydraulic capabilities of the project. In the first case construction would have continued for some 57 years, in the second for some 47 years. ${ }^{21}$ The alternative used for Yukon-Taiya was the Field Report estimate for a plant of 3,200,000 kilowatt capacity. Its construction would have required six years until completion of the project. In all cases it was assumed that construction would have started in the same year. A discussion of the estimating procedure used is contained in Appendix A.

The results of the investigation have been tabulated in table 1. Increases in required mill rates to cover construction costs under inflation for YukonTaiya are a relatively minor 4.8 percent. However, in the case of Rampart with its much longer construction time average mill rates would increase by 30.7 percent under Case II(A) and by 72.9 percent under Case I(A). These are substantial differences indeed which very radically alter the respective evaluation of the two projects. Trends in construction costs, therefore, cannot be disregarded in cases where construction times are long.

This issue is particularly critical in cases of long-term development programs that consist of a number of individual projects which, for their feasibility, depend on a costly common feature or component. In such cases the initial decision to proceed will often depend on the benefit-cost analysis of the whole program. But once the common component has been built even large cost changes for the remaining projects may not deter their construction simply because their, in terms of the overall development program, "marginal" benefit-cost ratios may remain above unity despite the fact that the average benefit-cost ratio for the development as a whole may have been reduced to less than one.

\section{CHANGES IN OPERATING COSTS}

Changes in operating costs may be of equal or even greater importance than changes in capital costs, particularly if alternatives exhibit large differences in their respective shares of capital and operating costs. Such differences are particularly marked between hydro-power plants on the one hand and

${ }^{21}$ This long construction time horizon would have been the result of the huge size of the reservoir which would require many years until it would be filled to capacity. As a result additional powerhouse construction and generator installations would have had to be stretched out over many years. 
TABLE 1

THE EFFECTS OF A TWO PERCENT ANNUAL RISE IN CONSTRUCTION COSTS ON THE EVALUATION OF RAMPART AND YUKON-TAIYA

\begin{tabular}{|c|c|c|c|c|c|}
\hline & 1 & 2 & 3 & 4 & 5 \\
\hline \multirow[b]{2}{*}{ PROJECT } & \multirow{2}{*}{$\begin{array}{c}\text { Total } \\
\text { Construction } \\
\text { costs in } \\
1964 \text { dollars } \\
\text { (millions) }\end{array}$} & \multirow{2}{*}{$\begin{array}{c}\text { Projected } \\
\text { Construc- } \\
\text { tion } \\
\text { Period } \\
\text { (years) } \\
\end{array}$} & \multicolumn{2}{|c|}{ Average Costs, mills/kwh } & $\begin{array}{c}\text { Increase } \\
\text { in }\end{array}$ \\
\hline & & & $\begin{array}{c}\text { No } \\
\text { Inflation }\end{array}$ & $\begin{array}{c}\text { Inflation } \\
2 \% \text { per } \\
\text { Year }\end{array}$ & $\begin{array}{c}\text { Required } \\
\text { Mill Rate } \\
\% \\
(\mathrm{Col} .3=100)\end{array}$ \\
\hline $\begin{array}{l}\text { Rampart } \\
\text { Case I(A) }\end{array}$ & 1,905 & 57 & 5.35 & 7.34 & 72.9 \\
\hline $\begin{array}{l}\text { Rampart } \\
\text { Case II(A) }\end{array}$ & 1,882 & 47 & 3.52 & 4.60 & 30.7 \\
\hline $\begin{array}{l}\text { Yukon-Taiya } \\
\text { Field'Report }\end{array}$ & $1,282.9$ & 6 & 2.90 & 3.04 & 4.8 \\
\hline
\end{tabular}

$1_{\text {Based on Rampart Field Report demand projection I(A) (normal growth }}$ utility-type load). Repayment period fifty years after completion of last construction. Interest rate $3 \%$. Costs include transmission lines.

${ }^{2}$ Based on Rampart Field Report demand projection II(A) (rapid load growth in early stages resulting in continuous full capacity utilization of the project). Costs include transmission lines.

${ }^{3}$ Assumes full output utilization after completion of construction. Costs do not include transmission lines.

${ }^{4}$ Mill rates do not rise in proportion to the inflator since the latter applies only to construction costs.

atomic or fuel-fired thermal stations on the other.

Let us look at an example. Let us assume that we have a choice between a hydro and a thermal power plant. The life expectancy and repayment period of the first is fifty years and of the second thirty-five years. Both have exactly the same output and the same capacity. Let us assume further that no technical considerations enter, ${ }^{22}$ and that the cost of capital in both cases is

${ }^{22}$ Orindarily, a hydro plant would be preferable because of its greater ability to adjust to varying load conditions and its capability of storing energy in the form of water. 
three percent. Estimated total annual costs at current price and wage levels are exactly the same. With equal output and equal capacity and no technical differences by assumption we would be indifferent in our choice between the two types of plants. However, this would hold true only if we were confident that present-day price and wage levels would remain unchanged during the lifeexpectancy of either plant. This, as we have already seen, is an unrealistic assumption. Prices and costs are likely to continue to rise but they will creep up at widely differeng rates in different sectors. 23 of the major categories wages are likely to increase at the fastest rate. This is as it should be, since it is the individual that should benefit from the increased productivity of our economy. But wage levels in the various sectors of our economy advance, by and large, at the same rate which means that in those sectors which do not experience technological improvements costs will have to go up. The two powerplants of our example fit exactly into this category. Once they are built their technology is more or less fixed. Some improvements through minor modifications may take place, but they will have little influence on the required factor inputs for the operation of the plants. It is also unlikely that there will be any major improvement in the productivity of the operating personnel. Operating, maintenance and repair expenditures, therefore, are likely to rise at the fastest rate.

For our example it was assumed that the average annual increase of these costs would be approximately $3 \%$. This, in the light of the post-war period, is probably not an unrealistic assumption. For the other large category of variable costs in the case of the thermal plant, the costs of fuel, a $1 \%$ annual price increase was assumed. 24 The respective shares of operating, maintenance, and repair expenditures in the case of the hydro plant were assumed to be fifteen percent of total annual average costs. Interest and depreciation account for the other 85 percent. In the case of the thermal power plant, $O$. M. \& R. expenditures account for twenty and fuel for forty-five percent of total average annual costs.

The effects of the various inflationary factors are shown in table 2. Columns (1) and (2) show the respective factor shares for the two plants in base period prices. Column (3) indicates the average expected annual price increase for each category. Columns (4) and (5) show the effects on the minimum required average mill rate, i.e. the rate which must be charged in order to cover all costs and assure repayment of all capital charges over the lifetime of the project. The result is hardly surprising. The mill rate for the

${ }^{23}$ All that is needed for the following analysis to hold is that relative prices and costs are going to change. This, as we have seen above, will be the case as long as we have uneven technological progress in different production processes.

${ }^{24}$ This rate may well be lower than likely fuel cost increases for many thermal power stations. However, the rate was chosen to reflect conditions in Alaska where large surpluses of natural gas are available. 
THE DIFFERENTIAL EFFECT OF PRICE INFLATION ON EQUIVALENT HYDRO AND THERMAL POWER PLANTS ${ }^{1}$

\begin{tabular}{|c|c|c|c|c|c|}
\hline & 1 & 2 & 3 & 4 & 5 \\
\hline & \multicolumn{2}{|c|}{$\begin{array}{c}\text { Distribution of } \\
\text { Costs in Base } \\
\text { Period Prices } \\
\%\end{array}$} & $\begin{array}{c}\text { Average Expected } \\
\text { Annual } \\
\text { Price Increase } \\
\% \\
\end{array}$ & \multicolumn{2}{|c|}{$\begin{array}{c}\text { Raquired Increase } \\
\text { in Average Mill } \\
\text { Rate to Cover } \\
\text { Expected Price Rise } \\
\% \\
\end{array}$} \\
\hline & Hydro & Thermal & & Hydro & Thermal \\
\hline $\begin{array}{l}\text { Depreciation } \\
\& \text { Interest }\end{array}$ & 85.0 & 35.0 & 0 & & \\
\hline Fuel & 0.0 & 45.0 & 1 & 9.5 & $19.0^{2}$ \\
\hline $\begin{array}{l}\text { O.M. \& R } \\
\text { Exp. }\end{array}$ & 15.0 & 20.0 & 3 & & \\
\hline TOTAL & 100.0 & 100.0 & & & \\
\hline
\end{tabular}

${ }^{1}$ Based on a 50 year repayment period for the hydro and a 35 year repayment period for the thermal powerplant. Interest rate $3 \%$.

${ }^{2}$ This estimate likely overstates the increase in average costs since the calculations assume a constant load factor over the life expectancy of the plant. This assumption would be unrealistic in a large power system in which new plants with lower operating costs are added during the lifetime of the project analyzed.

thermal powerplant increases by 19.0 percent, whereas the increase for the more capital intensive hydro plant is a much more modest 9.5 percent. What we also have to remember is the fact that average costs for the thermal alternative may increase substantially more if the rate of increase of fuel costs is higher than the modest one percent per year applied in our analysis. ${ }^{25}$

\section{CHANGES IN TECHNOLOGY}

Probably the most important factor influencing electric power planning

25

For example, if fuel costs were to rise at an average of $3 \%$ total average cost would increase by $41.3 \%$. 
today is the rapid pace of technological change that takes place in the design of thermal and particularly atomic powerplants. These changes represent a combination of several factors such as better heat rates, increased boiler pressures, more efficient fuel handling facilities, larger unit sizes and standardized production runs for powerplant components. As a result thermal generating costs per kilowatt-hour have fallen by fifty to sixty percent since the early 1950 's. The prospects for the future look even more promising. Today's large atomic powerplants of the boiling water type produce energy in the 2.5 to 4.0 mills/kwh range. Projections for the late 1990 's call for breeder reactors that are expected to generate electricity at costs between 1 to 2 mills/kwh. 26

As a result it might be advantageous for an electric power utility to expand its system by a shorter-life thermal rather than a longer-life hydro powerplant even if it happens that average production costs of the first thermal plant are higher than those of a hydro alternative. ${ }^{27}$ Three hypothetical plants have been shown in table 3. Their characteristics have been patterned after those discussed in the earlier section of the paper. To provide a convenient starting point it was assumed that they are cost equivalent when evaluated in terms of present price levels. The distribution of operating and capital costs and the magnitude of the cost escalators are the same as those shown in tables 1 and 2. Total costs for the Rampart-type plant increase by some 40.2 percent of which 30.7 percent are accounted for by the expected increase in construction costs. The Yukon-Taiya type hydro plant faces a much lower overall rise in costs simply because its construction period is relatively short. The average cost increase of the thermal plant sequence estimated at 18.8 percent is higher than the 14.3 percent of the second hydro plant. Nevertheless, adjusted average energy rates of the former are only $3.21 \mathrm{mills} / \mathrm{kwh}$ whereas they increase to $3.43 \mathrm{mills} / \mathrm{kwh}$ for the latter. This, of course, is a consequence of the shorter life expectancy of the initial, higher-cost thermal plant. Furthermore, it is useful to remember that the estimated costs for the thermal-atomic alternative are likely to be higher than those that may occur in reality because in our example we assumed not only a relatively long 35 year useful life for the original plant but also a constant plant utilization rate throughout.

${ }^{26}$ For a more detailed discussion of past and future generating costs see Gunter Schramm, "The Effects of Low Cost Hydro-Power...", op. cit.

${ }^{27}$ The following discussion is highly simplified since the analysis does not take into account such important variables as varying plant load factors, peaking load requirements and possible conversions of hydroplants from base-load to peak-load plants. It should also be remembered that the magnitude of the changes are significantly affected by the discount rates applied. However, neither of these factors invalidate the general conclusions drawn from the analysis. 


\section{EXAMPLE OF THE DIFFERENTIAL EFFECTS OF RISING COSTS AND CHANGING TECHNOLOGY ON ALTERNATIVE POWER PROJECTS ${ }^{1}$}

\begin{tabular}{|l|c|c|c|c|c|}
\hline $\begin{array}{l}\text { POWER PLANT } \\
\text { TYPE }\end{array}$ & $\begin{array}{c}\text { Average Costs } \\
\text { mills/kwh } \\
\text { Evaluated at } \\
\text { Present } \\
\text { Prices }\end{array}$ & $\begin{array}{c}\text { Cost Increase } \\
\text { due to } \\
\text { Construction } \\
\text { Cost Changes }\end{array}$ & $\begin{array}{c}\text { Cost } \\
\text { Increase } \\
\text { due to OM } \\
\text { \&R Cost } \\
\text { Changes }\end{array}$ & $\begin{array}{c}\text { Total } \\
\text { Cost } \\
\text { Cncrease }\end{array}$ & $\begin{array}{c}\text { Average Mill } \\
\text { Rate After } \\
\text { Adjustment } \\
\text { for all } \\
\text { Changes }\end{array}$ \\
\hline $\begin{array}{l}\text { Rampart IIA } \\
\text { (hydro) }\end{array}$ & 3 & 30.7 & 9.5 & 40.2 & 4.21 \\
\hline $\begin{array}{l}\text { Yukon-Taiya } \\
\text { (hydro) }\end{array}$ & 3 & 4.8 & 9.5 & 14.3 & 3.43 \\
Thermal-atomic \\
Powerplant \\
Sequence
\end{tabular}

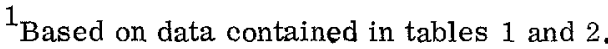

2

Thermal plant, 35 year life expectancy, average total production costs in present prices 3 mills $/ \mathrm{kwh}$; after 35 years thermal plant replaced by breeder reactor with average production costs in base year $(t+35)$ prices equal to 1.2 mills/kwh. Assumed cost escalation applied to both plants.

\section{CONCLUSIONS}

What are the conclusions that we have to draw from the foregoing discussion? We must conclude that the prevailing practice of evaluating benefits and costs in terms of present costs and prices is not only likely to lead to an understatement of actual costs, ${ }^{28}$ but also may lead to gross inefficiencies in project selection. This danger is particularly great in cases of hydro projects with long construction time horizons or long-term project sequences that depend

${ }^{28}$ The opposite might be true, of course, in cases where future benefits (or costs of supplies from alternative sources) are expected to increase. For example, if in their evaluation of the Feather River project Hirshleifer et al had made explicit allowance for possible rising costs of alternative future water supplies then their estimates of the net benefits of the project may well have been positive. See Hirshleifer, et al, op. cit., p. $335 \mathrm{ff}$. 
for their feasibility on some common facility. While the need to estimate future price relationships may seem to introduce new uncertaintie into project evaluations the use of prevailing prices is even less satisfactory. A somewhat inaccurate estimate of future changes, as long as it points in the right direction and as long as it is backed up by a sensitivity analysis that tests the effects of the assumptions on overall benefits and costs will provide a better and more realistic picture. Today this issue is of particular urgency since the traditional cost advantage of hydro over thermal alternatives is quickly disappearing. Given the very dramatic cost reductions expected from the introduction of second and third generation atomic power plants it becomes mandatory for any power system planner to take these expected changes explicitly into account. 
In order to evaluate the effects of inflationary price increases on the feasibility of a1ternative hydro projects it is necessary to compare the effects of these increases on the average mill rate required to assure repayment of project costs. This rate, expressed in mills per kilowatt-hour of energy sold, measures the average price which must be charged in order to cover all costs, $i$.e. interest and capital charges and ali operating and maintenance costs. Obviously, if construction costs increase over time the average mil1 rate must also increase. But because of the complex inter-relationship of cost and demand functions and the differences in these functions among different projects these milleage increases will not be proportional to the capital cost increases. Since construction costs form only one of the components of total costs the required milleage increase will be less than the overall increase of capital costs.

Isolating the effects of construction cost inflation requires that all other variables are being kept constant. These variables are the interest rate, the specified paymout period, the projected time path of construction, the operating and maintenance expenditures, and the projected annual power demand. These various expenditures and revenue streams have to be expressed in present value terms in order to make them comparable. The resulting equation is then solved for the unknown average mil1 rate. For reasons of convenience the end of the construction period has been chosen as the present value reference year of the equation. However, any other base would have given exactly the same result. The equation which is solved for $R$, the required mill-rate, takes the following form:

$$
\text { (1) } \sum_{i=i}^{j} A_{i}(1+r)^{j-i}+\frac{M}{n} \frac{(1+r)^{m}-1}{r}-R \sum_{i=1}^{j} q_{i}(1+r)^{j-i}=\left[\frac{R}{t}\left(Q n-\sum_{i=i_{1}}^{j} q_{i}\right)-\frac{M}{n}\right] \frac{(1+r)^{t}-1}{r(1+r)^{t}}
$$

where: ${ }^{1}$

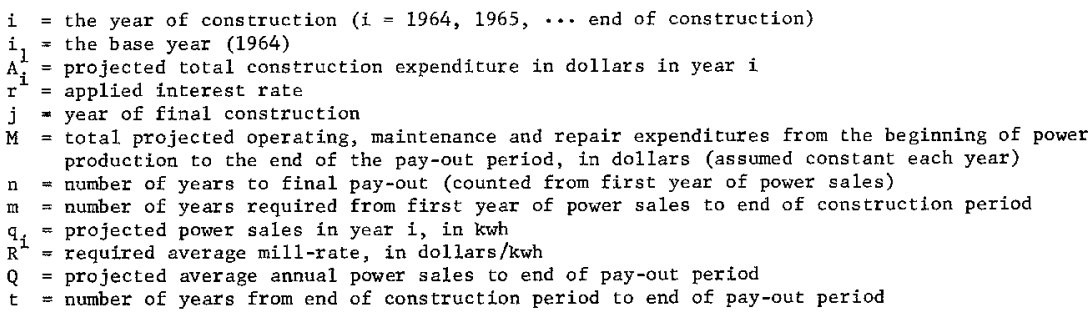

therefore

$$
\begin{aligned}
& \sum_{i=i}^{j} A_{i}(1+r)^{j-i} \\
& \frac{M}{n} \frac{(I+r)^{m}-1}{r}
\end{aligned}
$$$$
\begin{aligned}
& R \sum_{i=i}^{j} q_{i}(1+r)^{j-i} \\
& \frac{R}{t}\left(Q n-\sum_{i=i}^{j} q_{i}\right)
\end{aligned}
$$

$\frac{\mathrm{M}}{\mathrm{n}}$

$\frac{(1+r)^{t}-1}{r(1+r)^{t}}$
$=$ the sum of annual construction expenditures to the end of the construction period, compounded to the latter (which is used as the base year)

$=$ the sum of all O.M.\&R. expenditures from the first year of power sales to the end of the construction period, compounded to the base year

= total power sales to the end of the construction period, compounded to the base year, in dollars

= average annual power steles from the end of the construction period to the end of the pay-out period (to be discounted to the base year) expressed in dollars

= annual $0, M, \& R$. expenditures (to be discounted to the base year)

* present worth factor for a uniform series

\footnotetext{
$I_{T h e}$ use of the terms $M / n$ (the annual $0 . M . \& R$. expenditures) and $\left(Q n-\sum_{i=i} q_{i}\right) / t(t h e$ average
annual power sales in Kwh after completion of construction) was made
necessary by the way in which the data were tabulated in the original necessary by the way in which the data were tabulated in the original Rampart estimates. If $M$ and $Q$ had been enumerated for each year instead of being presented in sumarized form equation (1) could have been presented tn the much simpler appearing form of equation (7) below (excluding the cost escalators included in the latter). However, while the equation itself would have been simplified the actual calculations of the average mill rate would have been more cumbersome.
} 
In order to find the average mill rate required when construction costs are expected to increase it is necessary to multiply each annual construction expenditure $A_{i}$ by the projected price inflator.

$\sum_{i=i_{1}}^{j} A_{i}$ in the above equation therefore, must be replaced by the epxression

(2) $\sum_{i=1}^{j} A_{i}(1+k)^{i-i} I$

where:

$A_{i}=$ projected total construction expenditures in the year $i$ in non-inflated prices (as before)

$k^{i}=$ the expected average annual pxice increase of construction costs.

Total construction expenditures, appropriately inflated at the expected rate of price increases and compounded to the base year then are given by the expression:

(3) $\sum_{i=i}^{j} A_{i}(1+k)^{i-i} 1(1+r)^{j-i}$

Equations (1) and (3) [substituted in (1)] and the original Field Report data were used to estimate the figures in table 1 .

Similar adjustments using the appropriate inflator have to be made for operating, maintenance and repair expenditures. Equation (4) shows the modifications of equation (1) that are necessary to account for both capital and operating cost changes.

$$
\begin{aligned}
& \text { (4) } \sum_{i=i}^{j}\left[A_{i}(I+k)^{i-i} 1(1+r)^{j-i}\right]+\sum_{i=j-m}^{j}\left[\left[\frac{M}{n}(1+e)^{i-i} 1(1+r)^{j-i}\right]-\left[q_{i}(1+r)^{j-i} R\right]\right] \\
& =\frac{R}{t}\left[\mathrm{Qn}-\sum_{i=\mathbf{i}}^{j} q_{i}\right] \frac{(1+r)^{t}-1}{r(1+r)^{t}}-\sum_{i=j+1}^{j+t} \frac{M}{n}(1+e)^{i-i}{ }^{j}(1+r)^{j-i}
\end{aligned}
$$

where:

$e=$ the expected average annual cost increase of $0 . M . \& R$. expenditures and the definition of ali other variables remains as before.

\section{APPENDIX B}

\section{CURRENT VAIUE OF OUTPUT RISING AT THE SAME RATE}

AS THE GENERAT, PRICE LEVEL

While the preceding analysis was undertaken without taking the effects of general price level changes into consideration this will not always be appropriate. The following set of equations takes explifit account of both general and relative price level changes. As outlined above adjustments for general price changes can be made by either using current cost and prices and deflating the market rate of interest to the real rate, or by using the market rate and taking explicit account of expected price changes in all components of benefits and costs. Because we have to account for relative price changes in any case the second method is less cumbersome and, therefore, has been chosen.

It has been assumed that the discount rate represents the expected long-term average market rate applicable to the planning period. The use of this rate is appropriate as long as the planning agency (the government?) undertakes a large and approximately constant volume of projects every year so that no special weighting problems arise from the interaction of year to year variations in the discount rate on the one hand and lumpy expenditure patterns on the other. Furthermore, it has been assumed that all

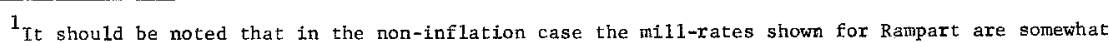
higher than the Field Report estimates. This is mainly the result of the application of compound interest rates throughout. The official Rampart projections used simple interest for components "under construction" Furthermore, for Case Study I the Field Report assuned large-scale sales of non-firm energy for which, however, there appeared to be no apparent market. For this reason no allowances for such additional sales have been made in oux calculations. 
expected price changes are going to be relatively uniform so that they can be approximated by annual percentage changes. Both assumptions could be modified but the resulting mathematical expressions would become more complicated. A further assumption that is made is that the real benefits of the output will remain constant so that their current value will rise at the same rate as the general price level. 1 The planning period has been set equal to the life expectancy of they hydro plant which is assumed to be 50 years after completion of construction. 2 The assumed life expectancy of the thermal plant is 30 years and that of the atomic plant sufficiently long to last at least until the end of the useful life of the hydro plant. No account has been taken of possible changes in load factors for any of the three plants. Given these assumptions, the present value of the real net benefits of the hydro plant is given by:

$$
\begin{aligned}
& \text { (5) } B_{1}^{N}=\sum_{i=i_{1}}^{i_{1}^{+j} 1^{+50}}\left[b_{1, i}\left(\frac{1+g}{1+r}\right]^{i-i_{1}}-A_{1, i}\left(\frac{1+k_{1,1}}{1+r}\right]^{i-i_{1}}-M_{1, i}\left(\frac{1+k_{1,2}}{1+r}\right]^{i-i_{1}}\right] \\
& \underset{\text { Benefits }}{\text { Net }}=\quad \text { Gross Benefits - Capita1 costs - 0.M.\&R. Expenditures }
\end{aligned}
$$

The present value of the net benefits of the thermal-atomic plant sequence is given by:

(6) $B_{2,3}^{N}=\sum_{i=i_{1}}^{i_{1}+j_{2}+30}\left[b_{2, i}\left(\frac{1+g}{1+r}\right]^{i-i_{1}}-A_{2, i}\left(\frac{1+k_{2,1}}{1+r}\right)^{i-i_{1}}\right.$ -

$$
\begin{aligned}
& \begin{array}{r}
\text { Total Net } \\
\text { Benefits }
\end{array}=\quad \begin{array}{r}
\text { Gross Benefits } \\
\text { Thermal Plant }
\end{array} \quad \text { Capital Costs Thermal Plant - } \\
& \left.M_{2, i}\left(\frac{1+k_{2,2}}{1+r}\right)^{i-i} 1-F_{2, i}\left(\frac{1+k_{2,3}}{I+r}\right)^{i-i_{1}}\right]+ \\
& \text { O.M.\&R. Therma1 Plant - Fuel Costs Thermal Plant + } \\
& \sum_{i=i_{1}+j_{2}+31-j_{3}}^{i_{1}^{+j} 1^{+50}}\left[b_{3, i}\left(\frac{1+g}{1+r}\right)^{i-i_{1}}-A_{3, i}\left(\frac{1+k_{3,1}}{1+r}\right]^{i-i_{1}}\right. \\
& \begin{array}{l}
\text { Gross Benefits } \quad-\quad \text { Capital Cost Nuclear Plant - } \\
\text { Nuclear Plant }
\end{array} \\
& \left.M_{3, i}\left(\frac{1+k_{3}, 2}{1+r}\right)^{i-i_{1}}-F_{3, i}\left(\frac{1+k_{3,3}}{1+r}\right)^{i-i_{1}}\right]+T\left(\frac{1}{1+r}\right)^{j_{1}+50} \\
& \text { O.M.\&R. Nuclear Plant - Fuel Costs Nuclear Plant + Residual Plant Value }
\end{aligned}
$$

where:

The first subscripts 1,2 and 3 in all variables refer to the hydro, the thermal and the atomic plants respectively:

$$
\begin{aligned}
& i_{1} \\
& A_{1, i} ; A_{2, i} ; A_{3, i} \\
& j_{1} ; j_{2} ; j_{3} \\
& k_{1,1} ; k_{2,1} ; k_{3,1} \\
& k_{1,2} ; k_{2,2} ; k_{3,2} \\
& k_{2,3} ; k_{3,3} \\
& r_{i_{1}}+j_{1}+50 \\
& M_{1, i} ; M_{2, i} ; M_{3, i}
\end{aligned}
$$

\section{$=$ the first year of construction}

$=$ construction expenditures for the three plants in year $i$ (expressed in $i$, prices), whereby the dollar costs of the future atomic plant have to reflect the best estimate of capital cost savings due to improved technology

$=$ the construction periods for the three plants in years;

$=$ the estinated average annual construction cost inflators for the three plants;

= the estimated average annual O.M.\&R. inflators for the three plants;

$=$ the estimated average annual increase in fuel costs for the thermal and atomic plant;

$=$ the long-term expected average market rate of interest;

$=$ the final year of the planning period for all three plants (equal to the assumed life expectancy of 50 years for the hydro plant);

$=$ the $0 . M . \& R$. expenditures for the three plants in year $i$ (expressed in $i_{1}$ prices), whereby the estimates for the future atomic plant must

$I_{\text {This assumption may not be realistic as we have already seen in the discussion on technological }}$ change. It will be removed in Section II,

${ }^{2}$ Given the expected technological change a longer planning horizon appears inappropriate even if the physical life expectancy of the plant is longer. Furthemore, at an interest rate of, for example, $5 \%$ a fifty year production period would account for over $90 \%$ of the present value of benefits even if the plant would operate forever. 
$F_{2, i} ; F_{3, i}$

$\stackrel{g}{T}$

$\mathrm{T}$

$b_{1, i} ; b_{2, i} ; b_{3, i}$

$\mathrm{B}_{1}^{\mathrm{N}}$

${ }^{\mathrm{N}}$

$\mathrm{B}_{2,3}$

reflect the best estimate of expected savings due to improvements in technology;

$=$ the fuel costs for the thermal and atomic plant in year $i$ (expressed

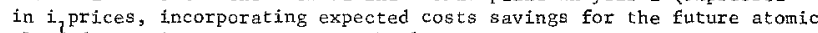
plant due to improvements in technology;

$=$ the average expected annual increase in the general price level

$=$ the remaining capital value of the nuclear plant at the end of the year $i_{I}+j_{1}+50$ (the end of the planning period);

$=$ the value of output of the three plants in year $i$ cexpressed in $i_{1}$ prices);

$=$ the present value of net benefits of the hydro plant;

Having found the present values of benefits and costs a compartson of the net benefits of both alternatives will show which one should be chosea. However, in order to make the model more realistic the various cost categories should be disaggregated so that account can be taken of more detailed price indexes. Furthermore, benefits and operating expenditures should be adjusted to reflect anticipated changes in load factors for both alternativas.

\section{MINIMIZATION OF COSTS APPROACH GIVEN TECHNOLOGICAL,} CHANGE AND LOAD FACTOR VARIATIONS

As was pointed out in the main text it is usually rather difficult to estabish the real value of electricity over time. This is so because, first, economies of scale in production and distribution make it necessary to leave the supply in the hands of pure monopolies, second, the short-run demand for electricity is highly inelastic (whereby short-run may mean a period of several years) and, third, the demand curve is continuously shifting outwards as a result of rising population, increasing production and rising real income levels. Because of the inelasticity of demend and the industry's market structure energy prices are usually subject to public regulation, whereby price levels are generaliy set on the basis of average costs. Average costs, in turn, are determined by the historical costs of investments and the current costs of $0 . M . \& R$. and Euel expenditures. Given these special conditions, public or private utilities notmally plan theix future investments on the basis of the lowest-cost alternative without making any attempt to establish the real value of their autput. ${ }^{2}$ Hence, the planning objective is to find the plant, or sequence of plants which promise to produce a given annual quantity of energy over the planning horizon at minimum costs, This, essentially, was the approach underlying the analysis in the text and in Appendix A.

In those cases in which the planned capacity addition (whose size is determined by the expected increase in demand and the retirement schedule of existing equipment) forms only a small part of total systens capacity, explicit account should also be taken of the expected reductions in capital and operating costs of future plant additions. While a hydro power plant, because of its very low $0, M$. daR. costs, will usually keep operating at full capacity throughout its life, thermal or atomic plant load factors will gradually decline as new capacity with lower operating costs per kilowatt-hour comes on 1 ine. 3

Given the mininization of cost approach outlined above these substitutions and changes in load factors require a modification of equations (5) and (6). The average generating costs per kilowatthour of the hydro alternative, then, can be found by: ${ }^{4}$

(7)

$$
\begin{aligned}
& \sum_{i=i_{1}}^{i_{1}+j_{1}+50} w_{1, i} R_{1}(1+r)^{i_{1}-i}= \\
& \sum_{i=i_{1}}^{i 1+j 1+50}\left[A_{1, i}\left(\frac{1+k_{1}, 1}{1+r}\right]^{i-i} 1+M_{1, i}\left(\frac{1+k_{1,2}}{1+x}\right)^{i-i_{1}}\right]
\end{aligned}
$$

${ }^{1}$ A compazison of net benefits is the appropriate criteria provided the plant capacities and energy outputs of both alternatives are the same and no capital rationing problems exist. If the latter is the case, specific account has to be taken of the foregone opportunity costs of limited investment funds. For a discussion of this issue see Peter 0. Steiner, "Choosing Among Alternative Investments in the Water Resources Field", American Economic Review, Vol. 49, No. 5, 1959.

$$
2 \text { For }
$$

Project For a justification of this approach see: Peter 0. Steiner, "The Role of Alternative Cost in Project Design and Selection", The Quarterly Journal of Economics, Vo1. LXXIX, No. 3, August 1965. For example, the analysis of the first oystex Creek plant estimared that the load factor of the coal alternative would fall from 90 to 38 per cent per year, while for the nuclear alternative (whose fuel costs were lower) it would fall from 90 to 53 per cent. Data fron: Jersey Central Fower \& Light Company, Report on Economic Analysis for Oyster Creek Nuclear Electric Generating Station, Feb. 17, 1964.

This formulation is essentialiy the same as that employed in equation (4). It should be noted that it disregards any potential jncrease in the value of the oucput if the plant can be converted to peaking load service. The resulting expression would be more complicated since new turbine-generators would have to be added and an estimate would have to be made of the relevant per kwh costs of the replacement base-load capacity. Moreover, to make the comparative analysis consistent, it would be necessary to estimate the future costs of additional peak-load capacity for the thermal-atomic plant sequence as well. 
where:

$$
\begin{array}{ll}
\mathrm{W}_{1, i} & =\text { the energy sold in year } i \text {, in kwh; } \\
\mathrm{R}_{1} & =\text { the average costs per kilowatt hour in dollars; }
\end{array}
$$

and the meaning of all other variables is the same as in equation (5).

For the thermal-atomic sequence account has to be taken of the declining load factors for the two plants which leads to a gradual reduction of total variable costs as future, lower-cost production units take over a growing share of the given output. 1 To simplify the resulting equation 0 .M. de. and fuel expenditures have been combined into a single energy-cost variable. The present values of energy costs of the thermal plant for each year are then given by: ${ }^{2}$

$$
\begin{aligned}
& P V E_{i=i_{1}+j_{2}+1}=E_{i}\left(\frac{1+k_{2,2}}{1+r}\right)^{i-i_{1}} \\
& \mathrm{PVE}_{i=i_{1}+j_{2}+2}=E_{1}\left(\frac{1+\mathrm{k}_{2,2}}{1+\mathbf{r}}\right)^{i-i} I\left[\left(1-\left[i-i_{1}-j_{2}-1\right] e_{2}\right)+e_{2}\left(\frac{1}{1+t_{2}}\right)\right]
\end{aligned}
$$

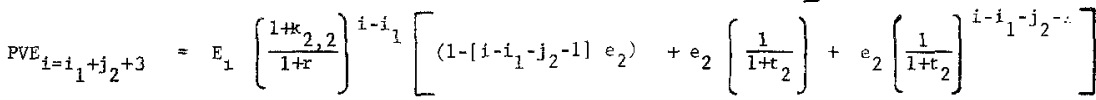

$$
\begin{aligned}
& \mathrm{PVE}_{i=\mathbf{i}_{1}+\mathbf{j}_{2}+4}=E_{i}\left(\frac{\mathrm{I}+\mathrm{k}_{2,2}}{1+\mathbf{r}}\right)^{i-i_{1}}\left[\left(1-\left[i-i_{1}-j_{2}-1\right] e_{2}\right)+e_{2}\left(\frac{1}{1+t_{2}}\right)+e_{2}\left(\frac{1}{1+t_{2}}\right)^{i-i}\right)^{-j} 2^{-2}+.
\end{aligned}
$$

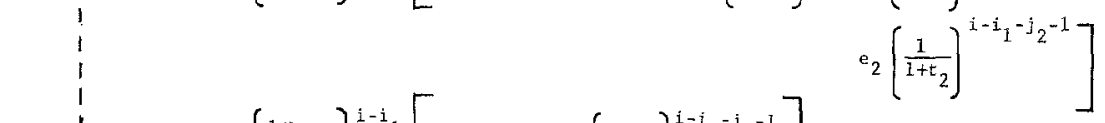

$$
\begin{aligned}
& P V E_{i=i_{1}+j_{2}+30}=E_{i}\left[\frac{1+k_{2,2}}{1+r}\right]^{i-i}\left[\cdots+e_{2}\left(\frac{1}{1+t_{2}}\right)^{i-i_{1}-j_{2}-1}\right]
\end{aligned}
$$

where:

$$
\begin{aligned}
& \mathrm{PVE}_{i} \quad \text { क the present value of total energy costs incurred in year } i \text {; } \\
& E_{i}{ }_{i} \quad=\text { the total energy costs in year } i \text { in year } i_{I} \text { prices; } \\
& e_{2} \quad=\text { the annual decline in the load factor of the thermal plant (assumed constant); } \\
& \dot{t}_{2} \quad=\text { the average expected rate of reductions in energy costs due to technological } \\
& \text { improvements incorporated in new plants; }
\end{aligned}
$$

and the definition of all other terms is the same as in equation (6).

It can be seen that the terms on the right form a geometric progression which in each case can be writcen as:

$$
\begin{aligned}
& \cdots e_{2}\left(\frac{1}{I+t_{2}}\right) \\
& \left.-e_{2}\left(\frac{1}{1+t_{2}}\right)^{-e_{2}\left(\frac{1}{1+t_{2}}\right)_{i-i_{1} j_{2}-2}^{i-i_{1}-j_{2}-1}}\right\}=e_{2} \frac{\left(\frac{1}{1+t_{2}}\right)^{i-i_{1}-j_{2}-i}}{\left(\frac{1}{1+t}\right)^{-1}}
\end{aligned}
$$

hence, the present value of total energy costs during the lifetime of the thermal plant becones:

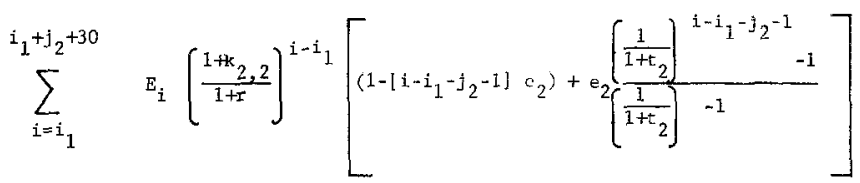

Ihere are wel1-supported expectations, for example, that average generating costs of new plants between the early 1960's and the end of the century will decline by something like $3 \%$ per year. However, in reality this change will likely not be a continuous one (as has been assumed in our analysis), so that the postulated continuous technological function may have to be replaced by another, nore complicated expression. For a discussion of expected cost changes see: Gunter Schram, "The Effects of Low-Cost Hydro Power---", op. cit.

${ }^{2}$ A roughly similar approach (which, however, did not consider rising factor costs) was recently employed by John V. Krutilla in a draft report to the Federal Power Commission entitled: On the Economics of Freservation or Development of the Lower Portion of the Helis Canyon, Washington, D.C., July 1, 1969, mitieo. 
A similar expression accounts for the energy costs of the nuclear plant.

Capital costs, on the other hand, are affected by technological change only when a new plant replaces an old one. The total average costs per kilowatt-hour for the thermal-atomic sequence can then be found by the equation:

$$
\begin{aligned}
& \text { (8) } \sum_{i=i}^{i_{1}+j_{1}+50} w_{2, i} R_{2}(1+r)^{i-i_{1}}=\sum_{i=i_{1}}^{i_{1}+j_{2}+30}\left[A_{2, i}\left(\frac{1+k_{2,1}}{1+r}\right)^{i-i_{1}}+\right. \\
& \text { Value of Total output = Capital Costs Thermal + } \\
& \left.E_{i}\left[\frac{i+k_{2}, 2}{1+x}\right]^{i-i_{1}}\left[\left(1-\left(i-i_{1}-j_{2}-1\right] e_{2}\right)+e_{2} \frac{\left(\frac{1}{1+t_{2}}\right)^{i-i_{1}-j_{2}-1}-1}{\left(\frac{1}{1+t_{2}}\right)-1}\right]\right)^{-1}+ \\
& \text { Energy Costs Thermal } \\
& \sum_{i=i_{1}+j_{2}+31-j_{3}}^{i_{1}+j_{1}+50} A_{2, i}\left(\frac{1+k_{2,1}}{1+r}\right)^{i-i_{1}}\left(\frac{1}{1+t_{1}}\right)^{j_{2}+31-j_{3}}+ \\
& \text { Capital Costs Nuclear + } \\
& \left.\left.E_{i}\left(\frac{1+k_{2,2}}{1+r}\right)^{i-i} 1\left(\frac{1}{1+t_{2}}\right)^{j_{2}+31-j_{3}}\left[\left(1-\left[i-i_{1}-j_{2}-31\right] e_{3}\right)+e_{3} \frac{\left(\frac{1}{1+t_{2}}\right)^{i-i_{1}-j_{2}-31}}{\left(\frac{1}{1+t_{2}}\right)^{-1}}\right]\right]^{-1}\right] \\
& \text { Energy Costs Nuclear } \\
& -T\left[\frac{1}{1+x}\right]^{j_{1}+50} \\
& \text { - Remaining Capita1 } \\
& \text { Value Nuclear }
\end{aligned}
$$

where:

$$
\begin{aligned}
& W_{2, i} \quad=\text { the energy sold in year } i, \text { in kwh; } \\
& \mathrm{R}_{2} \quad=\text { the average costs per kilowatt-hour; } \\
& A_{2, i} \quad=\text { the construction costs in year } i \text { estimated in year } i_{1} \text { prices and reflecting } \\
& \text { capital costs per kw installed capacity in year } i_{1} \text {; } \\
& \mathrm{k}_{2,1}=\text { the estimated average annual increase in construction costs for both thermal }
\end{aligned}
$$

The meaning of all other terms is the same as in equation (6).

It should be obvious that continuous inflators or rates of change should be used on $1 y$ if they represent the best available estimate. They should always be replaced by more specific information whenever it becomes availabie. 